\title{
Pre and post treatment symptomatic assessment of patient with STI receiving syndromic treatment
}

\author{
Hemanta Kumar Pradhan ${ }^{1, *}$, Pratibha Singh ${ }^{2}$, Garima Yadav ${ }^{3}$, Meenakshi Gothwal ${ }^{4}$ \\ ${ }^{\mathbf{1 , 3}, 4}$ Assistant Professor, ${ }^{2}$ Professor \& HOD, Dept. of Obstetrics and Gynaecology, ${ }^{1}$ Konaseema Institute of Medical Science \& \\ Research Foundation, Amalapuram Andhra Pradesh, ${ }^{2-4}$ All India Institute of Medical Sciences, Jodhpur, Rajasthan, India
}

*Corresponding Author:

Email: drhemantakumar@gmail.com

\begin{abstract}
Introduction: The aim of this study is to accesses the use of the syndromic approach towards managing sexually transmitted infections (STIs) in north western part of India and to make recommendations about the strengths and weakness of syndromic management algorithms and to determine if evidence supports its continued use.

Materials and Methods: Total of 412 patients diagnosed as STI based on clinical and physical examination were treated based on syndromic approach and finally 240 patients were recruited in the study. Diagnosis was made based on signs, symptoms and examination. Every symptomatic patient suggestive of STI was managed on the basis of algorithms of the syndrome approach and patients were again followed up after completion of treatment for assessment of clinical improvement/deterioration of signs and symptoms.

Results: Vaginal discharge (48.5\%, 194 out of 400) followed by lower abdominal pain $(46.75 \%, 187$ out of 400) were the most common complaints. On cervico-vaginal smear cytology, 31.70\%, $12.19 \%$ and $4.87 \%$ tested positive for bacterial vaginosis, leptothrix and candidiasis respectively. Syndromic approach for patients of STIs with symptoms of pain abdomen, white discharge P/V and itching P/V are statistically highly significant (Chi-Square Value 86.44 and its $\mathrm{p}$ value <0.0001) but for genital ulcer and urinary tract infection is statistically not significant. (Chi-Square Value $\sim 0.55$ and its $\mathrm{p}$ value is $>0.05$ ).

Conclusion: Syndromic management may be an effective method for clinical management of symptomatic STIs in low resource setting as illustrated in our finding. But further research is needed to determine the cost-benefit ratio of introducing laboratorybased screening into a comprehensive public health program for the control of commonly seen STIs in populations at risk for STIs.
\end{abstract}

Keyword: Diagnosis, Laboratory-based, Sexually Transmitted Infections (STIs), Syndromic approach, Treatment, World Health Organisation (WHO).

\section{Introduction}

Sexually transmitted infections (STI) are a major cause for adult morbidity worldwide. The importance of STIs has been more widely recognised since the advent of the HIV/AIDS epidemic and there is sufficient evidence that the control of STIs can reduce HIV transmission. ${ }^{1,2}$ The best management of STIs should include strategies for screening patients, partner identification, the administration of single drug with preferably single-dose and simplified treatment to improve compliance and increasing the accessibility of services. ${ }^{3}$ The introduction of new diagnostic tools and algorithms which are different from country to country and region to region has improved STI management considerably. Aetiological diagnosis using laboratory confirmation is considered the gold standard for the diagnosis and management of STIs ${ }^{4}$ however; it is not always possible and may result in delayed treatment and increased loss to follow-up. Moreover health care facilities in developing countries lack the equipment and trained personnel required to perform aetiological diagnosis of STIs. So World Health Organization (WHO) introduced the concept of "syndromic approach" to guide health workers using simple flowcharts or algorithms ${ }^{5}$ for management of sexually transmitted diseases especially in low-income countries. However, there has been some controversy regarding the on-going use of this approach. For this reason, prevention programs based on promotion of responsible sexual behaviour, early diagnosis and treatment, and reduction of infectiousness, has been implemented in many countries.

\section{Objectives}

To understand the use of the syndromic approach in managing sexually transmitted diseases in developing countries and to make recommendations about the strengths and weaknesses of syndromic management algorithms and to determine if evidence supports its continued use.

\section{Materials and Methods}

This cross-sectional study (observational research methods) was carried out at Obstetrics and Gynaecology outpatient department (OPD) of AIIMS, Jodhpur a tertiary care hospital over a period of one year.

Inclusion Criteria: All sexually active females in the age group of 18 years or more with the complaints suggestive of sexually transmitted infections were enrolled in the study.

Exclusion Criteria:

Pregnant females 
Post-menopausal women

Post hysterectomy women

Patients allergic to medication

Patients who did not take complete course of therapy or on immunosuppression therapy for more than $2 \mathrm{wk}$ within one year.

Patients having chronic medical illnesses such as diabetes, hypertension, tuberculosis, jaundice and terminally illness.

A total of 412 participants were included out of which 138 females and 12 males (all male participants) were lost to follow up, 06 were post-menopausal, 03 female were post hysterectomy and 12 patients suffered from chronic illness and one patient developed adverse drug reaction to medication. These were excluded from study. Finally 240 cases were recruited for the study.

Necessary clearances and permissions were obtained from the Institutional Ethics Committee AIIMS, Jodhpur for Human Research before starting the study. After obtaining a written informed consent, all females were enquired about their presenting complaints, menstrual history, obstetric history and sexual history. General physical examination along with local examination was done including $\mathrm{P} / \mathrm{S}$ and $\mathrm{P} / \mathrm{V}$. Routine biological sample were collected as required for additional information. Diagnosis was made based on signs, symptoms and examination. Every symptomatic patient suggestive of STI was managed on the basis of algorithms of the syndrome approach and patients were again followed up after completion of treatment for assessment of clinical improvement/deterioration of signs and symptoms.

All the data was entered into a Microsoft Excel Sheet and analysed by using Stat Disc free software version 13.0.1

\section{Observation}

Demographic details of patients of WHO syndromic approach for STI: A total of 400 participants were enrolled for the study. This study show most of the participants were female $(97.09 \%)$. The age range of female patients were 18-51 with median age of 31 years and most of them lie in the age group of 26-35 year $(47 \%)$. Most of the female patients are housewife $(57 \%)$ and married $(83.5 \%)$ and illiterate $(32.5 \%)$ those suffering from STIs. Most of the male partner are daily workers $(33.5 \%)$ and illiterate (27.5\%).Most of the family were socioeconomically (Modified BG Prasad scale) lower class (39\%).

Clinical and Laboratory details of patients of WHO syndromic approach for STI: White discharge P/V is the most common symptom (48.5\%) followed by pain abdomen $(47 \%)$ and highest rate of recurrence in vaginal discharge cases after treatment. White discharge $\mathrm{P} / \mathrm{V}$ with pain abdomen is the most commonly symptom seen in combination. On laboratory investigation cases positive for $\mathrm{HIV}, \mathrm{HBsAg}$ and RPR are $1.16 \%, 2.98 \%$ and $0.59 \%$ respectively. On cervico-vaginal smear most cases shows severe inflammatory smear $(36.58 \%)$ with $\mathrm{BV}$ is the most common organism isolated $(31.70 \%)$ followed by leptothrix (12.19\%).

Syndromic analysis of patients of WHO syndromic approach for STI: Syndromic approach for patients of STIs (Table 1) with pain abdomen before and after treatment have Chi-Square Value $=86.44$ and its $p$ value is $<0.0001$ which indicates highly significant. Similarly for white discharge P/V (Table 2) and itching P/V (Table 3) with Chi-Square Value $=54.28$ and its $\mathrm{p}$ value is $<0.0001$, Chi-Square Value $=86.65$ and its $p$ value is $<0.0001$ respectively which indicates also highly significant. But this same syndomic approach for genital ulcer and urinary tract infection is not significant. (Chi-Square Value $=0.55$ and its $\mathrm{p}$ value is $>0.05$, Chi-Square Value $=0.44$ and its $p$ value is $>0.05$ ) Syndromic approach for comparison of age with pain abdomen (Table 4) before and after treatment are all highly statistically significant (p value 0.0001 ) except the age group $>45$ which is slightly significant ( $\mathrm{p}$ value 0.0437)

Syndromic approach for comparison of age with white discharge (Table 5) before and after treatment are all highly statistically significant for all age groups ( $p$ value 0.0001 ) except for the age group $>45$ which is not significant. ( $p$ value 0.1015 )

Syndromic approach for comparison of age with itching P/V (Table 6) before and after treatment are all highly statistically significant for all age groups ( $p$ value 0.0001 ) except the age group $18-25$ year which is not significant. ( $\mathrm{p}$ value 0.5658 )

Syndromic approach for comparison of age with genital ulcer before and after treatment is not significant for age groups 18-25 \& 26-35 (p value $0.2331 \&$ 0.1979 ) and $\mathrm{p}$ value calculation is not possible for other groups.

Syndromic approach for comparison of age with urinary complain before and after treatment are not significant for age groups $18-25 \& 36-45$ ( $\mathrm{p}$ value 0.604 $\& 0.3001$ ) and $\mathrm{p}$ value calculation is not possible for other groups.

Syndromic approach for comparison of marital status with pain abdomen before and after treatment are statistically significant for both married and unmarried couple ( $p$ value 0.004 and 0.0001 ) but $p$ value calculation is not possible for other groups.

Syndromic approach for comparison of marital status with white discharge before and after treatment are statistically significant for married group ( $\mathrm{p}$ value 0.0001 ) but not significant for unmarried group ( $\mathrm{p}$ value 0.4001 ) and $p$ value not determined for other groups.

Syndromic approach for comparison of marital status with itching sensation before and after treatment are statistically significant for married couple( $\mathrm{p}$ value $0.0001)$ but $p$ value is not determined for other groups.

Syndromic approach for comparison of marital status with genital ulcer is statistically not significant 
for married couples ( $\mathrm{p}$ value 0.40002 ) whereas $\mathrm{p}$ value is not calculated in other groups.

Syndromic approach for comparison of marital status with urinary complain are statistically significant for married ( $\mathrm{p}$ value 0.0180 ) whereas $\mathrm{p}$ value is not calculated in other groups.

\section{Comparison study for syndromic approach}

Table 1: Comparison of abdominal pain before and after treatment

\begin{tabular}{|l|c|c|c|c|}
\multirow{2}{*}{ Before After } & Normal & Mild & Severe & Total \\
\cline { 3 - 5 } & & & & \\
\hline Normal & $50(96.15 \%)$ & $02(03.85 \%)$ & $00(0 \%)$ & $52(100 \%)$ \\
\hline Mild & $29(38.66 \%)$ & $44(58.66 \%)$ & $02(02.66 \%)$ & $75(100 \%$ \\
\hline Severe & $22(19.46 \%)$ & $77(68.14 \%)$ & $14(12.38 \%)$ & $113(100 \%)$ \\
\hline Total & $101(42.08 \%)$ & $123(51.25 \%)$ & $16(06.66 \%)$ & $240(100 \%)$ \\
\hline
\end{tabular}

Chi-Square Value $=86.44$ and its $p$ value is $<0.0001$, Highly Significant.

Table 2: Comparison of white discharge before and after treatment

\begin{tabular}{|l|c|c|c|c|}
\hline \multirow{2}{*}{ Before After } & Normal & Mild & Severe & Total \\
\cline { 2 - 5 } & & & & \\
\hline Normal & $43(95.55 \%)$ & $02(04.45 \%)$ & $0(0 \%)$ & $45(100 \%)$ \\
\hline Mild & $06(50.00 \%)$ & $06(50.00 \%)$ & $0(0 \%)$ & $12(100 \%)$ \\
\hline Severe & $63(34.42 \%)$ & $104(56.83 \%)$ & $16(08.74 \%)$ & $183(100 \%)$ \\
\hline Total & $112(46.66 \%)$ & $112(46.66 \%)$ & $16(06.66 \%)$ & $240(100 \%)$ \\
\hline
\end{tabular}

Chi-Square Value $=54.28$ and its $\mathrm{p}$ value is $<0.0001$, Highly Significant.

Table 3: Comparison of itching before and after treatment

\begin{tabular}{|l|c|c|c|c|}
\hline Before After & Normal Case & Mild Case & Severe Case & Total \\
\hline Normal Case & $168(99.40 \%)$ & $01(0.60 \%)$ & $0(0 \%)$ & $169(100 \%)$ \\
\hline Mild Case & $13(52 \%)$ & $12(48 \%)$ & $0(0 \%)$ & $25(100 \%)$ \\
\hline Severe Case & $25(54.34 \%)$ & $19(41.30 \%)$ & $2(04.34 \%)$ & $46(100 \%)$ \\
\hline Total & $206(85.83 \%)$ & $32(14.58 \%)$ & $2(0.83 \%)$ & $240(100 \%)$ \\
\hline
\end{tabular}

Chi-Square Value $=86.65$ and its $\mathrm{p}$ value is $<0.0001$, Highly Significant.

Table 4: Comparison of age with pain before and after treatment cases

\begin{tabular}{|c|c|c|c|c|c|c|c|}
\hline Age & Before & Normal & Mild & Severe & Total & P-value & Significance \\
\hline \multirow{4}{*}{$18-25$} & Normal & 18 & 0 & 0 & $18(20.69 \%)$ & \multirow{4}{*}{0.0001} & \multirow{4}{*}{ Significant } \\
\hline & Mild & 10 & 12 & 1 & 23 & & \\
\hline & Severe & 4 & 20 & 5 & 29 & & \\
\hline & Total & & & & 70 & & \\
\hline \multirow{4}{*}{$26-35$} & Normal & 16 & 1 & 0 & 17 & \multirow{4}{*}{0.0001} & \multirow{4}{*}{ Significant } \\
\hline & Mild & 7 & 17 & 0 & 24 & & \\
\hline & Severe & 12 & 30 & 5 & 47 & & \\
\hline & Total & & & & 88 & & \\
\hline \multirow{4}{*}{$36-45$} & Normal & 14 & 1 & 0 & 15 & \multirow{4}{*}{0.0001} & \multirow{4}{*}{ Significant } \\
\hline & Mild & 4 & 11 & 0 & 15 & & \\
\hline & Severe & 4 & 19 & 4 & 27 & & \\
\hline & Total & & & & 57 & & \\
\hline \multirow{4}{*}{$>45$} & Normal & 2 & 0 & 0 & 2 & \multirow{4}{*}{0.0437} & \multirow{4}{*}{ Significant } \\
\hline & Mild & 8 & 4 & 1 & 13 & & \\
\hline & Severe & 2 & 8 & 0 & 10 & & \\
\hline & Total & & & & 25 & & \\
\hline
\end{tabular}

$* \mathrm{p}<0.05$, Significant 
Table 5: Comparison of age with white discharge before and after treatment cases

\begin{tabular}{|c|c|c|c|c|c|c|c|}
\hline Age & $\begin{array}{l}\text { After } \\
\text { Before }\end{array}$ & Normal & Mild & Severe & Total & P-value & Significance \\
\hline \multirow{4}{*}{$18-25$} & Normal & 17 & 1 & 0 & 18 & \multirow{4}{*}{0.0001} & \multirow{4}{*}{ Significant } \\
\hline & Mild & 1 & 2 & 0 & 3 & & \\
\hline & Severe & 17 & 29 & 3 & 49 & & \\
\hline & Total & & & & 70 & & \\
\hline \multirow{4}{*}{$26-35$} & Normal & 10 & 0 & 0 & 10 & \multirow{4}{*}{0.0002} & \multirow{4}{*}{ Significant } \\
\hline & Mild & 2 & 2 & 0 & 4 & & \\
\hline & Severe & 24 & 41 & 9 & 74 & & \\
\hline & Total & & & & 88 & & \\
\hline \multirow{4}{*}{$36-45$} & Normal & 11 & 1 & 0 & 12 & \multirow{4}{*}{0.0002} & \multirow{4}{*}{ Significant } \\
\hline & Mild & 2 & 0 & 0 & 2 & & \\
\hline & Severe & 13 & 26 & 4 & 43 & & \\
\hline & Total & & & & 57 & & \\
\hline \multirow{4}{*}{$>45$} & Normal & 5 & 0 & 0 & 5 & \multirow{4}{*}{0.1015} & \multirow{4}{*}{$\begin{array}{c}\text { Not } \\
\text { Significant }\end{array}$} \\
\hline & Mild & 1 & 2 & 0 & 3 & & \\
\hline & Severe & 9 & 8 & 0 & 17 & & \\
\hline & Total & & & & 25 & & \\
\hline
\end{tabular}

$* \mathrm{p}<0.05$, Significant

Table 6: Comparison of age with itching before and after treatment cases

\begin{tabular}{|c|c|c|c|c|c|c|c|}
\hline Age & Before & Normal & Mild & Severe & Total & P-value & Significance \\
\hline \multirow{4}{*}{$18-25$} & Normal & 15 & 3 & 0 & 18 & \multirow{4}{*}{0.5658} & \multirow{4}{*}{$\begin{array}{c}\text { Not } \\
\text { Significant }\end{array}$} \\
\hline & Mild & 2 & 1 & 0 & 3 & & \\
\hline & Severe & 43 & 6 & 0 & 49 & & \\
\hline & Total & & & & $70(100 \%)$ & & \\
\hline \multirow{4}{*}{$26-35$} & Normal & 60 & 1 & 0 & 61 & \multirow{4}{*}{0.0001} & \multirow{4}{*}{ Significant } \\
\hline & Mild & 7 & 6 & 0 & 13 & & \\
\hline & Severe & 7 & 6 & 1 & 14 & & \\
\hline & Total & & & & 88 & & \\
\hline \multirow{4}{*}{$36-45$} & Normal & 43 & 0 & 0 & 43 & \multirow{4}{*}{0.0001} & \multirow{4}{*}{ Significant } \\
\hline & Mild & 4 & 1 & 2 & 7 & & \\
\hline & Severe & 4 & 3 & 0 & 7 & & \\
\hline & Total & & & & 57 & & \\
\hline \multirow{4}{*}{$>45$} & Normal & 17 & 0 & 0 & 17 & \multirow{4}{*}{0.0125} & \multirow{4}{*}{ Significant } \\
\hline & Mild & 1 & 0 & 0 & 1 & & \\
\hline & Severe & 4 & 2 & 1 & 7 & & \\
\hline & Total & & & & 25 & & \\
\hline
\end{tabular}

$* \mathrm{p}<0.05$, Significant

\section{Discussion}

STI is one of the most common health problems worldwide. The prevalence rate is far higher in developing countries where STI treatment is less accessible. $^{6}$

In the present study, a total 400 patients were included, which were mainly dominated by females (97.2\%). A study in Himachal Pradesh, India also reported the number of female patients were almost 3 times the number of male patients ${ }^{7}$ This may be due to effective contact tracing, spouse screening, changed definitions of STIs in the light of syndromic case management, clubbing of RTIs and media awareness campaigns. This trend has also been observed by other workers in some other states of India as well. 7,8

Another observation in the present study is that STI in females is noted at younger age group. Similar result was observed by Okonko et al. ${ }^{9}$ Age wise distribution of female patients shows that approximately $65 \%$ cases belongs to 25-35 years age but the peak age for maximum cases of STI was 25-30 years which is similar to several other studies. ${ }^{7,8}$ This is the sexually active group and at a high risk of behaviourally more vulnerable to STI acquisition.

On evaluating our clinical profile, vaginal discharge $(48 \%)$ and abdominal pain $(47 \%)$ followed by itching $\mathrm{P} / \mathrm{V}(17.5 \%)$ and urinary complains $(15 \%)$ were the common complaints in cases of STIs. Similar 
to this study, lower abdominal pain (42\%) and urinary complaints $(20 \%)$ were the most common complaints associated with STIs, in a study conducted in an urban slum of New Delhi. ${ }^{10}$

In our study on cervico-vaginal smear cytology, $31.70 \%, 12.19 \%$ and $4.87 \%$ tested positive for bacterial vaginosis, leptothrix and candidiasis respectively. Similar study performed by Vishwanath et al. ${ }^{11}$ concluded in their study that the prevalence of BV was $26 \%$, candidiasis $25.4 \%$, chlamydia infection $12.2 \%$, trichomoniasis $10 \%$ and syphilis $2.2 \%$ in a reproductive health clinic in Delhi, India.

Our aim of the study is to evaluate the accuracy (performance) of syndromic management of sexually transmitted infections (STIs) among women in North West part of India.

In our study syndromic approach for patients of STIs with pain abdomen before and after treatment with Chi-Square Value $=86.44$ and its $p$ value is $<0.0001$ which indicates statistically highly significant. Similarly for white discharge P/V Chi-Square Value $=54.28$ and its $\mathrm{p}$ value is $<0.0001$, which indicates statistically highly significant and for itching P/V ChiSquare Value $=86.65$ and its $p$ value is $<0.0001$ which indicates statistically highly significant. But this same syndomic approach for genital ulcer and urinary tract infection is not significant. (Chi-Square Value $=0.55$ and its $p$ value is $>0.05$, Chi-Square Value $=0.44$ and its $\mathrm{p}$ value is $>0.05$ ).

Another important finding in our study demonstrated the relationship between age as well as marital status with respect to STI in syndromic approach as age and marital status are the main contributory factor for STI all over world. In our study syndromic approach for pain is found to be statistically significant for all age group except $>45$ year group which is slightly significant whereas for white discharge it is not significant. This is explained that as age increases incidence of STI cases also decreases. But this syndromic approach is not significant for age group 18-25 which is not explained by our level. Similarly syndromic approach for pain in both married and unmarried group found to be significant but for white discharge it is not significant for unmarried group and also for itching it is significant for married group but $p$ value calculation is not possible in unmarried group.this is because of STI is more prevalent in married life. Multiple studies have demonstrated the efficacy of syndromic approach in the empirical diagnosis and treatment of patients presenting with symptom suggestive of STIs. Garcia et al. found syndromic management to be an effective and inexpensive method for the clinical management of symptomatic STIs ${ }^{12-16}$ which is in accordance with our present study except for minor variation. This type of variation in genital ulcer cases may be due to only few cases and for urinary complain is not possible in our level.
Our study has several strengths compared to other previous studies. It is a hospital-based study with extensive personal interview also enhancing its generalizability. Most studies on the association between STIs symptoms and tests have been carried out in particular groups that are, such as STD or antenatal clinic attendees, or sex workers.

However, this study has also some limitations that may have influenced our findings. Firstly this study was performed in OBG OPD at AIIMS, Jodhpur a hospital based study (so not representative of the overall population) so that only women (only few male patient came) patients who agreed to be tested for STIs were included in the analysis, thereby ignoring the possible systematic differences between women who consented to be tested for STIs and those who did not. For example, if women without or with fewer STIs symptoms consented to be tested, this might have led to an underestimation of the true association between STIs symptoms and tests. Also some of the reported symptoms could have been caused by infections not measured in the study. This might have also led to an underestimation of the true association between STIs symptoms and tests. Secondly sample size is comparatively small, thirdly all asymptomatic patients suffering from STIs are not taken into consideration and finally all symptomatic patients which were actually not suffering from STIs had given treatment though there was no requirement so chances of antibiotics resistance. So analysis of the complete cases can be biased if there was a systematic difference between cases with observed data and those with unobserved data.

\section{Conclusion}

Syndromic management may be an effective method for clinical management of symptomatic STIs in low resource setting as illustrated in our finding. It is simple, cost effective, and capable of yielding rapid diagnosis for immediate treatment. On the other hand it fails to detect a large number of infections that are asymptomatic or not recognized by patients and is inadequate as a primary method for STI control in low resource settings. Further research is needed to determine the cost-benefit ratio of introducing laboratory-based screening into a comprehensive public health program for the control of commonly encounter STIs in populations at risk for STIs. Many symptomatic women without these STI receive broad-spectrum antibiotics, so new approaches are needed to improve syndromic STI control. Though syndromic management may present as a simplified and affordable approach for sexually transmitted infections in limited resource settings but laboratory etiological diagnosis is considered the gold standard for diagnosis and management of STIs. 


\section{Acknowledgements}

Authors would like to thanks Director AIIMS, Jodhpur for allowing us to use hospital data for preparation of this manuscript.

Funding: The authors declare no funding sources for this study.

Conflict of Interest: The authors declare no conflict of interests regarding the publication of this paper.

Ethical Approval: The study was approved by the Institutional Ethics Committee, AIIMS, Jodhpur, India.

\section{References}

1. WHO. Prevalence and incidence of selected sexually transmitted infections; Chlamydia trachomatis, Neisseria gonorrhoea, syphilis and Trichomonas vaginitis. Geneva: World Health Organisation, 2011.

2. WHO. Sexually transmitted infections. Geneva: World Health Organisation, 2011.

3. Catchpole M. sexually transmitted infections: control strategies. Br Med J 2001;322:1135-1136.

4. Workowski KA, Levine WC and Wasserheit JN. U.S. Centers for disease control and prevention guidelines for the treatment of sexually transmitted diseases: an opportunity to unify clinical and public health practice. Ann Intern Med 2002;137:255-262.

5. WHO. Guidelines for the management of sexually transmitted infections. Geneva: World Health Organisation, 2003.

6. Chin J. Public health surveillance of AIDS and HIV infections. Bull World Health Organ 1990;68:529-36.

7. Ganju SA, Sharma NL. Initial assessment of scaled-up sexually transmitted infection intervention in Himachal Pradesh under National AIDS Control Program - III. Indian J Sex Transm Dis 2012;33:20-4.

8. Devi SA, Vetrichevvel TP, Pise GA, Thappa DM. Pattern of sexually transmitted infections in a tertiary care centre at Puducherry. Indian J Dermatol 2009;54:347-9.

9. Okonko IO, Akinpelu AO, Okerentugba PO. Prevalence of sexually transmitted infections (STIs) among attendees of AFRH centre in Ibadan, South western Nigeria. Middle East J Sci Res 2012;11:24-31.

10. Garg S, Sharma N, Bhalla P, Sahay R, Saha R, Raina U, et al. Reproductive morbidity in an Indian urban slum: Need for health action. Sex Transm Infect 2002;78:68-9.

11. Vishwanath S, Talwar V, Prasad R, Coyaji K, Elias CJ, de Zoysa I. Syndromic management of vaginal discharge among women in a reproductive health clinic in India. Sex Transm Infect 2000;76:303-6.

12. Adams EJ, Garcia PJ, Garnett GP, Edmunds WJ, Holmes KK (2003) the cost-effectiveness of syndromic management in pharmacies in Lima, Peru. Sex Transm Dis 30:379-387.

13. Garcia P, Hughes J, Carcamo C, Holmes KK (2003) Training pharmacy workers in recognition, management, and prevention of STDs: district randomized controlled trial. Bull World Health Organ 81:806-814.

14. Garcia PJ, Gotuzzo E, Hughes JP, Holmes KK (1998) Syndromic management of STDs in pharmacies: evaluation and randomised intervention trial. Sex Transm Infect 74 Suppl 1:S153-158.

15. Garcia PJ, Carcamo CP, Chiappe M, Holmes KK (2007) sexually transmitted and reproductive tract infections in symptomatic clients of pharmacies in Lima, Peru. Sex Transm Infect 83:142-146.

16. Viberg N, Mujinja P, Kalala W, Kumaranayake L, Vyas S, et al. (2009) STI management in Tanzanian private drugstores - practices and roles of drugsellers. Sex Transm Infect. 